This is a self-archived - parallel published version of this article in the publication archive of the University of Vaasa. It might differ from the original.

\title{
Blockchain and Organizational Characteristics: Towards Business Model Innovation
}

Author(s): Shahzad, Khuram

Title: Blockchain and Organizational Characteristics: Towards Business Model Innovation

Year: $\quad 2020$

Version: Accepted manuscript

Copyright (C)2020 Springer. This is a post-peer-review, pre-copyedit version of an article published in Advances in Creativity, Innovation, Entrepreneurship and Communication of Design: Proceedings of the AHFE 2020 Virtual Conferences on Creativity, Innovation and Entrepreneurship, and Human Factors in Communication of Design, July 16-20, 2020, USA. The final authenticated version is available online at: http://dx.doi.org/10.1007/978-3-030-51626-0_9.

\section{Please cite the original version:}

Shahzad, K. (2020). Blockchain and Organizational Characteristics: Towards Business Model Innovation. In: Markopoulos, E., Goonetilleke, R. S., Ho, A. G. \& Luximon, Y. (eds.) Advances in Creativity, Innovation, Entrepreneurship and Communication of Design: Proceedings of the AHFE 2020 Virtual Conferences on Creativity, Innovation and Entrepreneurship, and Human Factors in Communication of Design, July 16-20, 2020, USA, 80-86. Cham: Springer. https://doi.org/10.1007/978-3-030-51626-0_9 


\title{
Blockchain and Organizational Characteristics: Towards Business Model Innovation
}

\author{
Khuram Shahzad \\ School of Technology and Innovations/Innovation and Entrepreneurship InnoLab \\ University of Vaasa, \\ Yliopistonranta 10, 65200 Vaasa, Finland
}

\begin{abstract}
Blockchain seems to challenge the current business models by providing opportunities for new value creation. However, several research gaps remain in literature in evaluating how firms can leverage new approaches to innovation management and opportunities created by blockchain. Supporting organizational characteristics affecting digital innovation management process also need attention in order to challenge the traditional theories while developing unique fundamental assumptions between innovation processes and outcomes. Thus, blockchain and organizational characteristics need to be understood as an encompassing, over-arching and interrelated ecosystem in digital innovation management. Grounding on digitalization and innovation management, this research conceptualizes how blockchain technology and supporting organizational characteristics (i.e., R\&D investment, strategic alignment, cultural support, top management knowledge and involvement, insights from customers and end-users) can be integrated for business model innovation. This research develops a conceptual framework involving multi-disciplinary collaborative actions that strengthen and empower business model innovation.
\end{abstract}

Keywords: Blockchain technology; Organizational characteristics; Digitalization; Business model innovation; Industrial ecosystem; Innovation management process; Digital innovation

\section{Introduction}

Grounding on digitalization and innovation management, this research conceptually determines how blockchain technology and supporting organizational characteristics (i.e., R\&D investment, strategic alignment, cultural support, top management knowledge and involvement, insights from customers and end-users) can be integrated in a smarter way to develop business model innovation that is a key factor in enabling innovation management process. This research helps industrial firms to find ways in decreasing silos of disruptive technological challenges and promotes organizational harmony in implementation of such technologies. Scholars such as [1] define digitalization as "use of digital technologies to innovate a business model and pro-vide new revenue streams and value-producing opportunities in industrial ecosystems" which holds that it is more than just the application of numerous digital technologies. Based on this definition, this research includes the perspectives of digital technologies as well as the value-producing opportunities of developing business model innovation. Similarly, the concept of blockchain has increasingly gained ground in the literature on strategy, innovation management, entrepreneurship and digital economy. Scholars have developed a set of definitions and concepts in a variety of contexts, employing blockchain with different labels and, in some cases, with different meanings and purposes e.g., digital chain, smart contracts etc. Scholars such as [2] defined blockchain as "a digital, decentralized and distributed ledger in which transactions are logged and added in chronological order with the goal of creating permanent and tamper-proof records". 
As a decentralized technology, blockchain eliminates the maneuvering and some-how exploiting role of middleman as well as the transactions costs and time. The entire process of authorizing transactions and adding blocks in a public blockchain is completely distributed in a way that no single regulatory authority exists. It provides encrypted transactions data with more security and verified platforms on a network using cryptographic algorithms [3], [4]. Thus, blockchain seems to challenge current business models and provide opportunities for new value creation and a significant role in developing business model innovation, however, prior literature neglected it [5]. Several research gaps remain in literature in evaluating how firms can leverage new approaches to innovation management and opportunities created by blockchain. It can be grounded on digital innovation management to transform their business models in order to attain sustainability benefits. Yet, the prior literature remains unclear in developing an understanding of value-creation opportunities derived from blockchain [1] and how does this technology can contribute to digital innovation management. The prior discussion of blockchain remained with very few high profile examples, which necessitate conducting a rigorous action research in order to develop rich understanding of how firms adopt blockchain and begin to integrate it into their operations [4]. Furthermore, supporting organizational characteristics that affect successful digital innovation management process [6] also need attention in order to challenge the traditional theories on innovation management while developing unique fundamental assumptions. Thus, blockchain and organizational characteristics need to be understood as an encompassing, overarching and interrelated ecosystem in digital innovation management. There remains an immense need to align and integrate the blockchain with organizational characteristics to ensure the successful innovation management of firms through developing business model innovation.

Against this backdrop and the crucial need to develop successful innovation management process, efforts should be made to build research-based knowledge and novel theorizing on digital innovation management that draws on the rich and rapidly emerging research on blockchain. More attention should be given to the organizational characteristics that support in the concrete, viable and scalable implementation of blockchain developing business model innovation. This research develops a conceptual framework of next generation blockchain-based digital innovation management that involves multidisciplinary collaborative actions strengthening and empowering business model innovation.

\section{Significance of the Research in Relation to Current Knowledge}

Digitalization has become a major enabling and transformational force in rapid technological changes and emergence of disruptive technologies [1], [7]. In current digitalized era, firms are under immense pressure requiring revolutionizing their innovation management processes. The growing importance of this notion is driving firms to overwhelmingly reinvent the way their operations and processes are conducted in industrial value chains through using several current technologies such as IloT, block-chain, cloud computing, advanced algorithms, Al, automation, big data and analytics etc. [8], [1]. As building blocks of fourth industrial revolution - known as Industry 4.0 [9], these digital technologies possess such capabilities that can exponentially transform the spectrum of innovation management and competences by offering significant potential for value-creation - thriving in a digital world. This next generation "digital disruption" [10] in innovation management is challenging existing theories thus requiring firms to capitalize on digital transformation of operating models [11], [12]. The concept of "Factories of the Future 2020" delivers European added value by helping firms to make the necessary adaptations in terms of innovative and digitalized excellence and flexibility, including skills development, to capitalize on the increasing demand for more customized and higher-quality products. Open innovation perspective drive firms to extend their 
product development and innovation capabilities with external partners providing them with valuable competence and knowledge. This rise of global knowledge economy has intensified a critical need for research-based knowledge and novel theorizing on digital innovation management that draws on the rich and rapidly emerging digital technologies.

Digitalization is compelling every phase of the innovation process - from gathering and evaluating customer insights, to producing and vetting ideas, to designing and manufacturing new products, and, finally, to tracking the triumph of products once launched. Scholars [13] have segmented firms into three different strategic innovation models (i.e., need seekers, market readers and technology drivers). First category i.e. need seekers usually involve customers in generating new ideas to develop products and services, while market readers as fast followers create ideas by carefully observing their markets, customers, and competitors, concentrating mainly on generating value through incremental innovations to existing products. Technology drivers rely mainly on their in-house technological capability to cultivate new products and services, generating both breakthrough innovation and incremental change to meet known and unknown needs of their customers via new technology. However, each category of firm in this innovation models require new approaches to innovation management and opportunities created by digitalization. Similarly, the Forbes' top ten World's Most Innovative Companies (from "ServiceNow" at No.1 to "Facebook" at No. 10) have a distinctly digital feel, meaning that their innovation management models are mainly based on digitalization of their operations.

Digital innovation management including these disruptive technologies does not only contribute to automation and optimization of the processes (increasing the efficiency by $15-20 \%$ ) but also provide value-producing opportunities and profitability ( $20 \%$ of revenue generation) by reducing transaction costs [14] and minimizing errors [1]. Technological applications however are not enough for innovation excellence as several incumbent firms are ill prepared; it necessitates transformation to business model innovation [15], based on digital technologies such as blockchain. Evidently, several firms have had substantial triumph and business development opportunities with the full range of digital technologies. However, there might be some challenges of implementation and their proper usage. According to recent research, only $1 \%$ of $\mathrm{CIO}$ reported blockchain implementation and only $8 \%$ of respondents get involved in short-term planning and pilot planning [16]. The report based on [17] states that $74 \%$ of their respondents see a convincing business case using blockchain technology while $34 \%$ respondents stated that their firms have initiated blockchain adoption in some way or the other.

There is a limited attention on blockchain in literature and a lack of consensus re-mains around the value and limitation of this technology, reflecting an immature state of the literature [4], [1]. Digital technologies and business model innovation also face challenges of continuous improvement in keeping up with their competitors and offering long-term value to their customers [18]. Digital technologies are not as simple as to "plug and play" thus necessitates to ensure developing an understanding across teams in a way that everyone involved in using these technologies are trained enough and using them with the same pace [6]. This requires firms to develop such an organizational culture that support in integration of these digital technologies.

\subsection{Blockchain and Business Model Innovation}

Blockchains is an emerging technology which has drawn significant attention from energy supply firms, start-ups, technology developers, financial/non-financial institutions, national governments and the academic community [19], [5]. Blockchain has the potential to transform applications and redefine the 
digital economy [20]. The capabilities of blockchain run beyond bitcoin facilitating current technology applications to be massively upgraded [21]. It is known as a distributed ledger technology/not a single technology but rather functions on a pile of technologies that include the internet as an infrastructure and utilizes the blockchain practice for keeping transaction records and establishing consensus rules [22]. Blockchain is currently revolutionizing industrial applications by providing solutions while driving economic revolution on a worldwide scale and making the whole operational process more transparent as it is unchallengeable and redefines trust that allow secure, quick, reliable, and transparent public/private results. The longer the chain, the harder it is to make modifications in previous blocks, and thus the higher the level of trust [3], [5], [4], [20]. For example, in high-value businesses of diamond trading, this technology can transform the whole supply chain transparent and trustworthy.

The potential role of blockchain could actually transform the business model and process of innovation management by making the whole process transparent and trustworthy. This will enable firms to reconsider their ways of conducting businesses. Blockchain is emerging in several fields, however, it's significant role in the "core" of business - business model innovation and innovation process need to be defined at first hand, as it would help firms to rethink about their purpose of being in digital era. Blockchain technology provides several prospects to cultivate businesses model in-novation. [5] called for further empirical research on how blockchain technology effects business model of creating, delivering and capturing value consisting nine building blocks; 1) customer segments, 2) value proposition, 3) channels, 4) customer relationships, 5) revenue streams, 6) key resources, 7) key activities, 8) key partnerships, and 9) cost structure. They also have argued that consortia-led blockchain projects public blockchain projects can engender architectural and radical innovations, which can be interesting to find out in empirical settings. Similarly, [1] stressed that future research could focus on the business model innovation of value creation, value delivery and value capturing opportunities from emerging blockchain technology. They argued that blockchain and smart contracts could play an intriguing role in changing the value-capture component of business model as well as in future company competitiveness by enabling increased transparency among multiple actors.

\subsection{Organizational Characteristics Supporting Innovation Management Process}

The ability to innovate and to be innovative can be regarded very important for firms to be able to secure their survival and success. The importance of being bold characterizes firms and their inclination towards digital innovation management. The firms that practice the supporting organizational characteristics (e.g., R\&D spending, strategic alignment, cultural support, top-management involvement, and involving customers and end-users) can outperform their competitors by building an integrative network in innovation management process and digitalization [13]. Spending on internal and external R\&D have a significant role in process innovativeness by offering the most relevant knowledge [23] and facilitating the adoption and implementation of technologies such as blockchain. R\&D spending among the "Global Innovation 1000" overall increased 11.4 percent in 2018, to a record high of $\$ 782$ billion, reflecting R\&D spending increases in all regions and nearly all industries [13]. Furthermore, the firms who consider commencing blockchain initiatives need to consider strategic alignment between their innovation strategy and business strategy. It means the in-novation strategy (introducing novel components) must be aligned with business strategy and value creation in making the transition to advanced service business model [24]. Involving customers directly to generate new ideas help them to approach market first [25], [5]. 
Rapid transformation in technological innovation also requires firms to undergo an internal cultural shift that nurtures innovation management process for sustainable development amidst global competition [1]. Top management knowledge significantly facilitate successful innovation management process and business model innovation as top management involvement in R\&D investments and strategy create business opportunities by aligning their capabilities with innovation programs. Moreover, topmanagement's role is crucial in the management of innovativeness, especially as the driver and communicator of change [26], [13]. Lastly, the insights from customers and end-users can lead to better decisions that will resonate throughout the life cycle of product development, necessitating customers and end-users' involvement in creating, capturing and delivering value in industrial ecosystem [13], [6].

\section{Concluding Remarks}

This research develops a conceptual framework involving multi-disciplinary collaborative actions that strengthen and empower business model innovation. However, blockchain is a rather new concept and it seems it is finding its applications in different fields. Blockchain and organizational characteristics need to be understood as an encompassing, overarching and interrelated ecosystem in digital innovation management. Thus, a holistic understanding of blockchain, its processes, implementation, and practices is required for further research in order to produce a clear understanding for both research and practice. It necessitates exploring and mapping the usage of blockchain technology by firms to automate transactions as well as revising and renewing their business model in order to achieve successful innovation management process. In addition, current developments in digital innovation management research require further investigation on exploring and integrating the organizational characteristics that support in implementing blockchain technology in their value chain. Exploiting blockchain technology and supporting organizational characteristics go hand-in-hand with business model innovation and innovation management processes, which requires an integrated framework and process that define how value can be created, delivered and captured among value chain actors [1].

References

1. Parida, V., Sjödin, D., Reim, W.: Reviewing Literature on Digitalization, Business Model Innovation, and Sustainable Industry: Past Achievements and Future Promises. Sustainability 11, 391 (2019)

2. Treiblmaier, H.: The Impact of the Blockchain on the Supply Chain: A Theory-Based Research Framework and a Call for Action. Supply Chain Management: An International Journal 23(6), 545--559 (2018)

3. Reyna, A., Martín, C., Chen, J., Soler, E., Díaz, M.: On Blockchain and Its Integration with lot. Challenges and Opportunities. Future Generation Computer Systems 88, 173--190 (2018)

4. Cole, R., Stevenson, M., Aitken, J.: Blockchain Technology: Implications for Operations and Supply Chain Management. Supply Chain Management: An International Journal 24(4), 469--483 (2019)

5. Morkunas, V.J., Paschen, J., Boon, E.: How Blockchain Technologies Impact Your Business Model. Business Horizons 62(3), 295-306 (2019)

6. Jaruzelski, B., Loehr, J., Holman, R.: The global Innovation 1000: Navigating the Digital Future. Strategy+Business, 73 (2013)

7. Gauthier, C., Bastianutti, J., Haggège, M.: Managerial Capabilities to Address Digital Business Models: The Case of Digital Health. Strategic Change 27(2), 173--180 (2018) 
8. Bharadwaj, A., El Sawy, O.A., Pavlou, P.A., Venkatraman, N.: Digital Business Strategy: Toward a Next Generation of Insights. MIS Quarterly 471--482 (2013)

9. Gilchrist, A.: Industry 4.0: The Industrial Internet of Things. Apress, Berkeley, CA (2016)

10.Weill, P., Woerner, S.L.: Thriving in an Increasingly Digital Ecosystem. MIT Sloan Management Review 56 (4), 27 (2015)

11.Lerch, C., Gotsch, M.: Digitalized Product-service Systems in Manufacturing Firms: A Case Study Analysis. Research-Technology Management 58(5), 45--52 (2015)

12.Parida, V., Sjödin, D.R., Lenka, S., Wincent, J.: Developing Global Service Innovation Capabilities: How Global Manufacturers Address the Challenges of Market Heterogeneity. Re-search-Technology Management 58(5), 35--44 (2015)

13.Jaruzelski, B., Chwalik, R., Goehle, B.: What the Top Innovators Get Right. Strategy+Business 93 (2018)

14.Shahzad, K., Ali, T., Takala, J., Helo, P., Zaefarian, G.: The Varying Roles of Governance Mechanisms on Ex-post Transaction Costs and Relationship Commitment in Buyer-Supplier Relationships. Industrial Marketing Management 71, 135--146 (2018)

15.Porter, M.E., Heppelmann, J.E.: How Smart, Connected Products are Transforming Companies. Harvard Business Review 93(10), 96--114 (2015)

16.Gartner.: Blockchain $\quad$ Status $2018 . \quad$ Market Adoption Reality, https://www.gartner.com/doc/3869693/blockchain-status-market-adoption, (2018)

17.Deloitte: $2018 \quad$ Global Blockchain Survey, https://www2.deloitte.com/insights/us/en/topics/understanding-blockchain-potential/global-

blockchain-survey.html, (2018)

18.Sjödin, D.R., Parida, V., Lindström, J.: Barriers and Conditions of Open Operation: A Customer Perspective on Value Co-creation for Integrated Product-service Solutions. International Journal of Technology Marketing 12(1), 90--111 (2017)

19.Andoni, M., Robu, V., Flynn, D., Abram, S., Geach, D., Jenkins, D., ... \& Peacock, A.: Blockchain Technology in the Energy Sector: A Systematic Review of Challenges and Opportunities. Renewable and Sustainable Energy Reviews 100, 143--174 (2019)

20.Helo, P., Hao, Y.: Blockchains in Operations and Supply Chains: A Model and Reference Implementation. Computers \& Industrial Engineering 136. 242--251 (2019)

21.Underwood, S.: Blockchain Beyond Bitcoin. Communications of the ACM 59(11), 15--17 (2016)

22.Smith, T.D.: The Blockchain Litmus Test. In: 2017 IEEE International Conference on Big Data (Big Data), pp. 2299--2308. IEEE Press (2017)

23.Rodriguez, J.A., Wiengarten, F.: The Role of Process Innovativeness in the Development of Environmental Innovativeness Capability. Journal of Cleaner Production 142, 2423--2434 (2017) 
24.Foss, N.J., Saebi, T.: Fifteen Years of Research on Business Model Innovation: How Far Have We Come, and Where Should We Go? Journal of Management 43(1), 200--227 (2017)

25.Adams, P., Freitas, I. M.B., Fontana, R.: Strategic Orientation, Innovation Performance and the Moderating Influence of Marketing Management. Journal of Business Research 97, 129--140 (2019)

26.Singh, S.K., Gupta, S., Busso, D., Kamboj, S.: Top Management Knowledge Value, Knowledge Sharing Practices, Open Innovation and Organizational Performance. Journal of Business Research, in press (2019) 